\title{
Restrained TGO Growth in YSZ/NiCrAIY Thermal Barrier \\ Coatings by Modified Laser Remelting
}

\author{
Changhao Zhao, Meng Zhao, Muhammad Shahid, Min Wang, Wei Pan* \\ State Key Laboratory of New Ceramics and Fine Processing, School of Materials Science and \\ Engineering, Tsinghua University, Beijing 100084, PR China
}

\begin{abstract}
Thermal barrier coatings (TBCs) are widely applied in high temperature gas turbines and jet engines to protect the superalloy components. Due to oxygen transfer through topcoat and the oxidation of bond-coat alloy, a thin layer of thermally grown oxide (TGO) will generate between the ceramic topcoat and the metallic bondcoat of TBCs after long-term operation. Cracking and spalling are often observed at the topcoat-TGO and TGO-bondcoat interfaces since the thickening of TGO layer may lead to strong tensile stress. Previously, laser remelting process has been developed as an effective way in restraining the TGO growth. In the present research, preheating laser remelting and sol-gel repairing laser remelting were respectively employed to further decelerate the TGO growth by reducing the number density and average size of vertical cracks in the topcoat. After 100h isothermal oxidation, the TGO growth rate of the modified laser remelted specimens are much lower than the conventional laser remelted specimens, which shows the potentiality of preheating and sol-gel repairing as effective promotions of laser remelting process in restraining the TGO growth.
\end{abstract}

Key word: Thermal barrier coatings; TGO; Laser remelting; Preheat; Sol-gel 


\section{Introduction}

Thermal barrier coatings (TBCs) are widely applied in gas turbines and jet engines to protect the superalloy components, such as blades and vanes, from the high temperature combustion and harsh oxidizing atmosphere $[1,2]$. Currently, TBC systems mainly consist of a ceramic topcoat for thermal insulation, and a metallic bondcoat providing the adhesion between the topcoat and the superalloy substrate [3,4]. During the high temperature operation, a thin layer of thermally grown oxide (TGO) will generate between the topcoat and bondcoat, composed mainly of $\mathrm{Al}_{2} \mathrm{O}_{3}$ and some other oxides, such as chromia $\left((\mathrm{Cr}, \mathrm{Al})_{2} \mathrm{O}_{3}\right)$, spinel $\left(\mathrm{Ni}(\mathrm{Cr}, \mathrm{Al})_{2} \mathrm{O}_{4}\right)$ and nickel oxide $(\mathrm{NiO})$, which are all formed due to the oxygen diffusion through the ceramic topcoat $[5,6]$.

Due to the mismatching of elastic modulus and thermal expansion coefficients, the growth of TGO will increase the tensile stress at the topcoat-TGO and TGO-bondcoat interfaces, leading to severe cracking and spalling of the ceramic topcoat $[7,8]$. State-of-the-art TBC, yttria stabilized zirconia (YSZ), has a high oxygen permeability and has been identified as good oxygen ion conductor [3,9]. Besides, the topcoat fabricated by air plasma spray (APS), contains various defects, such as the typical lamellar stacking microstructure, splat cracks and high volume porosity, which can also accelerate the oxygen diffusion through the topcoat [10-13]. In order to restrain the TGO growth, several kinds of surface-sealing treatments have been developed to optimize the surface condition of the YSZ topcoat, such as laser remelting, aluminum phosphate sealing, chemical densification and sol-gel process $[14,15]$. Among them, laser remelting process has been proven to be effective, because the remelted dense layer at the topcoat surface can reduce the oxygen conduction and therefore slow down the TGO growth [16-19]. However, a segmented crack network 
perpendicular to the topcoat surface will generate after remelting and solidification [20, 21]. Propagation of the cracks during the high temperature operation will result in a "shortcut" for oxygen transferring, and finally destroys the oxygen resistance of the remelted layer [22-24]. Increasing the temperature of the superalloy substrate can reduce the temperature gradient along the TBC system during the APS process and thereby minimize the size of cracks in the ceramic topcoat, which may also be effective during the laser remelting process [25-27]. Besides, due to the low oxygen conductivity and good high temperature stability, $\mathrm{Al}_{2} \mathrm{O}_{3}$ has been identified as a potential protecting layer on TBCs to modify the surface microstructure and provide the oxygen resistance [28-30]. Effect of $\mathrm{Al}_{2} \mathrm{O}_{3}$ on the microstructure and oxidization behavior of YSZ coatings has been studied [31-34]. However, researches are still lacking about minimizing the concentration and size of cracks in the laser remelted layer by $\mathrm{Al}_{2} \mathrm{O}_{3}$ modification.

In the present research, preheating of the substrate was employed to control the cracks in the laser remelting layer, and a sol-gel process was also conducted to generate a thin film of $\mathrm{Al}_{2} \mathrm{O}_{3}$ on the surface of the laser remelting layer to cover the cracks. Microstructure and oxidization behavior of these modified specimens were investigated. Effect of these two processes on the TGO growth was also discussed.

\section{Experimental procedures}

A nickel-based superalloy (Inconel, GH 4169, CISRI, Beijing, China) in the dimension of $10 \times 11 \times 5 \mathrm{~mm}$ was selected as the substrate. Ni-25Cr-7Al-1Y powders with a particle size between $15 \mu \mathrm{m}$ to $45 \mu \mathrm{m}$ (BGRIMN, Beijing, China) and $7 \mathrm{wt} . \% \mathrm{Y}_{2} \mathrm{O}_{3}$ stabilized $\mathrm{ZrO}_{2}$ powder with a particle size between $75 \mu \mathrm{m}$ to $125 \mu \mathrm{m}$ (BGRIMN, Beijing, China) were respectively 
used as the raw materials for bondcoat and topcoat. The bondcoat was deposited by high velocity oxy-fuel spraying (HVOF, K2, GTV, Germany) and the topcoat was prepared by air plasma spraying (APS, F6, GTV, Germany). Specific parameters of the HVOF and APS processes are shown in table I. The TBC specimens were then laser remelted by a pulsed Nd: YAG laser (HYK-200, Hairun Creater, Beijing, China) with 1mm diameter standard circular pulses. The wavelength was $1064 \mathrm{~nm}$ and the mean power was $80 \mathrm{~W}$. The scanning speed was $12 \mathrm{~mm} / \mathrm{s}$ and the overlap of the pulses was $40 \%$.

Preheating laser remelting was applied to control the cracking of the topcoat after laser remelting. The specimens were preheated for 20min in an electric furnace (CMF 1100, MTI, Hefei, China) holding at $600^{\circ} \mathrm{C}$. After dwelling, the specimens were immediately laser remelted with the same parameters mentioned above. On the other hand, $\mathrm{Al}_{2} \mathrm{O}_{3}$ coat was also adopted by sol-gel method on the surface of laser remelted specimens to repair the cracks. 20wt.\% acidic $\mathrm{Al}_{2} \mathrm{O}_{3}$ sol (Sinopharm Chemical Reagent, Beijing, China) was coated on the surface of the specimens by a spin coater (pw-4a, Chemat Technology, Shanghai, China). Then the specimens were heat treated at $600^{\circ} \mathrm{C}$ for $5 \mathrm{~h}$ with a heat rate of $5^{\circ} \mathrm{C} / \mathrm{min}$ to remove the organics. Finally, the specimens were sintered at $1000^{\circ} \mathrm{C}$ for $8 \mathrm{~h}$ to form the dense layer of $\mathrm{Al}_{2} \mathrm{O}_{3}[32,33]$. The laser remelting processes applied in the present research are summarized in table II.

In order to investigate the TGO growth in the specimens treated by different laser remelting processes, the specimens were furnace aged in air at $1000^{\circ} \mathrm{C}$ for $100 \mathrm{~h}(\mathrm{CWF} 1200$, Carbolite, Derbyshire, UK). Then the TGO layer was observed on the cross section of the specimens by SEM (Mira3 LHM, TESCAN, Brno, Czechia) and the thickness of them was also measured from the back scattered electron (BSE) images (JSM 7001F, JEOL, Tokyo, 
Japan). Finally, the TGO growth rate was calculated by the TGO thickness and the oxidation time.

\section{Results and discussions}

Fig.1 shows the surface images of as-sprayed APS and laser remelted coating, respectively. The surface of laser remelted coating appeared to be smoother than that of APS coating. Meanwhile, some laser spots residual are remained on the surface after the laser remelting process. Furthermore, SEM images of the surface of the APS and the laser remelted coatings are shown in Fig.2. Specifically, as-sprayed coatings have a rough surface with melted zone, unmelted particles, cracks and pores. Although YSZ is a good solid electrolyte for oxygen ion conduction at high temperature, the defects will further enhance the oxygen conduction through the coating. Instead, the surface of the laser remelted coatings is much smoother and denser. Most of the pores are eliminated by the remelting. However, some vertical cracks generated during the cooling, which are mainly caused by the rapid solidification and large thermal gradient along the coating [19, 20]. Furthermore, Fig.3 shows the cross section microstructure of the laser remelted coatings. A dense remelted layer formed at the surface of the coating in contrast to the defective and porous unmelted part beneath.

After $100 \mathrm{~h}$ oxidation at $1000^{\circ} \mathrm{C}$, TGO of different thickness have formed at the topcoat and bondcoat interface for both coatings with and without laser remelting. Fig. 4 shows the BSE images of their cross sections. Clearly, TGO in the non-remelted specimens is thicker than that of laser remelted ones, confirming that laser remelting can restrain the TGO growth rate. It should be noticed that the TGO thickness is not uniform. This is mainly affected by two factors; the one is the lamellar structure of the APS coating and the random cracks, voids 
and pores and the other is the roughness of the bond coat surface. These random distributed defects will lead to the variation of oxygen diffusion and non-uniform TGO growth. The rough bond coat surface with convex and concave also induces a non-uniform TGO thickness layer $[35,36]$.

In order to accurately evaluate the TGO growth, we defined a specific TGO thickness $(\delta)$ as the ratio of the cross section area and the length of the TGO layer, as shown in Fig.5. The measurement of the area of TGO layer was conducted using the Photoshop software while the length of TGO was obtained by AutoCAD at the same place in the BSE image. For each specimen, the area and length of the TGO were measured at 10 different places. Then the average value of the TGO thickness was calculated and is shown in table III.

Specifically, the TGO thickness of non-remelted and laser remelted specimens are $5.03 \pm$ $1.17 \mu \mathrm{m}$ and $4.34 \pm 0.73 \mu \mathrm{m}$. The TGO growth rate calculated by the TGO thickness and time are respectively $0.0503 \pm 0.0117 \mu \mathrm{m} / \mathrm{h}$ and $0.0434 \pm 0.0073 \mu \mathrm{m} / \mathrm{h}$ for non-remelted and laser remelted specimens, which are shown in Fig.6. A $14 \%$ reduction of the TGO growth rate is achieved by the laser remelting process, indicating that the laser remelted dense layer is beneficial to the oxygen resistance of the YSZ topcoat. However, as mentioned above, the vertical cracks in the dense remelted layer, which are generated by the rapid solidification and large thermal gradient, may limit the oxygen resistance or even cause the damage of the layer [20-22].

To control the cracking of the dense remelted layer, preheating was applied. As shown in Fig.1, the surface of preheating laser remelted specimen seems to be even smoother than that of specimen without preheating. SEM images of the surface of laser-remelted specimens with 
and without preheating are shown in Fig.7. It can be observed that the cracks on the surface of preheated specimens are clearly less than that of specimens without preheating. Furthermore, the crack proportion of the surface can be quantitatively evaluated using the surface image analysis from SEM images. As shown in Fig.8, the area of all the cracks on the surface can be selected by Photoshop software and the crack proportion can be calculated according to the pixels. The evaluation and calculation were applied at five different section for each specimen which is shown in Fig.9. As summarized in table IV, crack proportions on the surface of laser remelted specimens with and without preheating are $4.34 \pm 0.43 \%$ and $6.46 \pm 0.39 \%$, respectively. This indicates that preheating is an effective way to reduce the crack proportion on the remelted layer, which may lead to better oxygen resistance.

After $100 \mathrm{~h}$ oxidization at $1000^{\circ} \mathrm{C}$, the thickness and the growth rate of the TGO could be calculated from the SEM images of the cross section of the preheating laser remelted specimen (Fig.4c). As shown in Fig.6 and listed in table III, the TGO thickness in preheating lase remelted specimen is $3.7 \pm 0.72 \mu \mathrm{m}$ and the TGO growth rate is $0.0370 \pm 0.0072 \mu \mathrm{m} / \mathrm{h}$, respectively, which are about $15 \%$ lower than the laser remelted specimen without preheating, and about $26 \%$ lower than the as-sprayed coating. Clearly, preheating can improve the effect of laser remelting process in restraining the TGO growth.

In present study, effect of $\mathrm{Al}_{2} \mathrm{O}_{3}$ sol-gel repairing laser remelting is also investigated. In the surface image of sol-gel repairing laser remelted specimen (Fig1), the laser spots disappeared from due to a cover of new $\mathrm{Al}_{2} \mathrm{O}_{3}$ coating. As shown in Fig.10a the SEM image of the surface of the $\mathrm{Al}_{2} \mathrm{O}_{3}$ sol-gel repairing laser remelted specimen reveals that the cracks on the dense remelted layer are mainly sealed by a thin film, although there are still some small cracks remained due to the shrinkage of the gel during densification. EDX measurement 
results (Fig.10b, Fig.10d) indicate the composition of film is alumina and the $\mathrm{Al}_{2} \mathrm{O}_{3}$ infiltrates into the cracks. However, XRD test could not identify the $\alpha-\mathrm{Al}_{2} \mathrm{O}_{3}$ phase (the thermodynamically stable phase above $1000^{\circ} \mathrm{C}$ ) on the surface since the amount of $\mathrm{Al}_{2} \mathrm{O}_{3}$ is too small. Since $\mathrm{Al}_{2} \mathrm{O}_{3}$ is an oxygen barrier material restraining the oxygen diffusion across the coating, low TGO growth rate can be expected in $\mathrm{Al}_{2} \mathrm{O}_{3}$ sol-gel repairing laser remelted specimens [37-40].

After high temperature oxidation test, the TGO layer in the $\mathrm{Al}_{2} \mathrm{O}_{3}$ sol-gel repairing laser remelted specimen is even thinner (shown in Fig.4d), for which the TGO thickness is $3.8 \pm$ $1.00 \mu \mathrm{m}$ and the TGO growth rate is $0.0380 \pm 0.0100 \mu \mathrm{m} / \mathrm{h}$, respectively. Comparing with as-sprayed coating, the reduction of TGO growth rate is about $24 \%$ lower, which is similar with that of preheating laser remelting process.

In summary, TGO growth rate of laser remelted, preheating laser remelted and sol-gel repairing laser remelted specimens have been obviously reduced in comparison to as-sprayed APS coatings. It is well known that the oxygen transportation from the atmosphere to the topcoat-bondcoat interface through the YSZ coating has two major mechanisms. One is the oxygen diffusion in the gas phase via the interconnected cracks, pores and voids; the other one is the oxygen ion migration and conduction by means of a discrete hopping process through the YSZ lattice [21]. In the present research, the biggest TGO growth rate for as-sprayed coating is owing to both of the two mechanisms. For laser remelted specimen, the pores are eliminated and the crack concentration and size are also controlled. Thus, the gas phase diffusion is retarded and the TGO growth rate is smaller than that of as-sprayed coating. For preheating laser remelted specimen, the crack concentration in the dense remelted layer is reduced by about $30 \%$, therefore the gas phase diffusion is further retarded and the TGO 
growth rate is even smaller. For sol-gel repairing laser remelted coating system, the YSZ grains are covered by the oxygen barrier $\mathrm{Al}_{2} \mathrm{O}_{3}$ film and the cracks are also partly sealed. Therefore, both oxygen transportation mechanisms are retarded. The TGO growth rate is smaller than that of the laser remelted specimen.

Comparing with the as-sprayed coating, the TGO thickness (after $100 \mathrm{~h}$ at $1000^{\circ} \mathrm{C}$ ) reduction of laser remelted, preheating laser remelted and sol-gel repairing laser remelted specimens are $13 \%, 26 \%$ and $24 \%$ respectively. These results are compatible with some previous researches, such as $13 \%\left(100 \mathrm{~h}\right.$ at $\left.1000^{\circ} \mathrm{C}\right)$ after conventional $\mathrm{Al}_{2} \mathrm{O}_{3}$ covering [41], 28\% $\left(100 \mathrm{~h}\right.$ at $\left.1100^{\circ} \mathrm{C}\right)$ after nanostructured $\mathrm{Al}_{2} \mathrm{O}_{3} / \mathrm{YSZ}$ compositing [37] and $26 \%$ (240h at $1200^{\circ} \mathrm{C}$ ) after laser remelting [21]. It should be noticed that the TGO thickness reduction $(26 \%)$ of laser remelted coating after $240 \mathrm{~h}$ oxidation at $1200^{\circ} \mathrm{C}$ is twice more than that only laser remelted $(13 \%)$ in the present research. The difference may be caused by the oxidation temperature and time.

\section{Conclusions}

In order to restrain the TGO growth in TBCs, three different methods based on laser remelting process were employed to YSZ/NiCrAlY TBCs. The TGO thickness and growth rate in the specimens were evaluated discussed. Laser remelting can reduce the TGO growth rate by about $13 \%$. Preheating laser remelting can reduce the surface crack proportion generated during the laser remelting, thereby further decreases the TGO growth rate decreased by about $26 \%$. Moreover, $\mathrm{Al}_{2} \mathrm{O}_{3}$ film can cover the surface of YSZ coating and seal the cracks. Therefore, $\mathrm{Al}_{2} \mathrm{O}_{3}$ sol-gel repairing laser remelting can decrease the TGO growth rate by $24 \%$. 
These results provide new perspectives to restrain the TGO growth in YSZ/NiCrAlY thermal barrier coatings.

\section{Acknowledgement}

This research is supported by National Science Foundation of China (No.51072088 and $51272120)$. 


\section{References}

1. M. Nejati, M.R. Rahimipour, I. Mobasherpour, A.H. Pakseresht, Microstructural analysis and thermal shock behavior of plasma sprayed ceria-stabilized zirconia thermal barrier coatings with micro and nano $\mathrm{Al}_{2} \mathrm{O}_{3}$ as a third layer, Surf. Coat. Technol. 282 (2015) $129-138$.

2. R. Swadz 'ba, J. Wiedermann, M. Hetman 'czyk, L. Swadz 'ba, B. Witala, G. Moskal, B. Mendala and $\iota$. Komendera, Microstructural examination of TGO formed during pre oxidation on Pt - aluminized Ni - based superalloy, Mater. Corros. 65 [3] (2014) 319-323.

3. Hui Dong, Guan-Jun Yang, Cheng-Xin Li, Xiao-Tao Luo, and Chang-Jiu Li, Effect of TGO Thickness on Thermal Cyclic Lifetime and Failure Mode of Plasma-Sprayed TBCs, J. Am. Ceram. Soc. 97 [4] (2014) 1226-1232.

4. J. Toscano, R. Vaßen, A. Gil, M. Subanovic, D. Naumenko, L. Singheiser, W.J. Quadakkers, Parameters affecting TGO growth and adherence on MCrAlY-bond coats for TBC's, Surf. Coat. Technol. 201 (2006) 3906-3910.

5. W.R. Chen, X. Wu, B.R. Marple, D.R. Nagy, P.C. Patnaik, TGO growth behaviour in TBCs with APS and HVOF bond coats, Surf. Coat. Technol. 202 (2008) 2677-2683.

6. Rong Xu, Xue Ling Fan, Wei Xu Zhang, T.J. Wang, Interfacial fracture mechanism associated with mixed oxides growth in thermal barrier coating system, Surf. Coat. Technol. 253 (2014) 139-147.

7. Shunda Wen, Jinxia Song, Shengkai Gong, Huibin Xu, Yafang Han, Failure behaviors of TBCs on $\mathrm{Ni}_{3} \mathrm{Al}$ base alloy IC6A during room temperature tensile test and stress rupture test under the condition of $1100^{\circ} \mathrm{C} / 100 \mathrm{MPa}$, Intermetallics 15 (2007) 801-804.

8. W.R. Chen, X. Wu, B.R. Marple, P.C. Patnaik, The growth and influence of thermally grown oxide in a thermal barrier coating, Surf. Coat. Technol. 201 (2006) 1074-1079.

9. J. Toscano, R. Vaßen, A. Gil, M. Subanovic, D. Naumenko, L. Singheiser, W.J. Quadakkers, Parameters affecting TGO growth and adherence on MCrAlY-bond coats for TBC's, Surf. Coat. Technol. 201 (2006) 3906-3910.

10. Guy Antou, Ghislain Montavon, Franc Hlawka, Alain Cornet, Christian Coddet, Frédérique Machi, Modification of thermal barrier coating architecture by in situ laser remelting, J. Eur. Ceram. Soc. 26 (2006) 3583-3597.

11. M.R. Dorfman, D. Sporer, and P. Meyer, Sulzer Metco (U.S.) Inc, Thermal Spray Technology Growth in Gas Turbine Applications, ASM International 5A (2013) 280-286.

12. Dongsheng Wang, Zongjun Tian, Lida Shen, Zhidong Liu, Yinhui Huang, Effects of laser remelting on microstructure and solid particle erosion characteristics of $\mathrm{ZrO} 2-7 \mathrm{wt} \% \mathrm{Y}_{2} \mathrm{O}_{3}$ thermal barrier coating prepared by plasma spraying, Ceram. Int. 46 (2014) 8791-8799.

13. Reza Ghasemi, Reza Shoja-Razavi, Reza Mozafarinia, Hossein Jamali, Laser glazing of plasma-sprayed nanostructured yttria stabilized zirconia thermal barrier coatings, Ceram. Int. 39 (2013) 9483-9490. 
14. Xiao-feng Zhang, Ke-song Zhou, Xu Wei, Bo-yu Chen, Jin-bing Song, Min Liu, In situ synthesis of $\alpha$-alumina layer at top yttrium-stabilized zirconia thermal barrier coatings for oxygen barrier, Ceram. Int. 40 (2014) 12703-12708.

15. Kun Zhang, Shuhong Ning, Chao Ren, Xiaowei Luo, Lixin Dong, Hui Chen, Yedong He, Improvement of oxidation resistance of spatial-network $\mathrm{Al}_{2} \mathrm{O}_{3} / \mathrm{YSZ}$ composite coatings by chemical densification, Surf. Coat. Technol. 266 (2015) 105-112.

16. Hui Chen, Yunfei Hao, Hongying Wang, and Weijie Tang, Analysis of the Microstructure and Thermal Shock Resistance of Laser Glazed Nanostructured Zirconia TBCs, J. Therm. Spray. Technol. 19 [3] (2010) 558-565.

17. Raheleh Ahmadi-Pidani, Reza Shoja-Razavi, Reza Mozafarinia, Hossein Jamali, Laser surface modification of plasma sprayed CYSZ thermal barrier coatings, Ceram. Int. 39 (2013) 2473-2480.

18. Raheleh Ahmadi-Pidani, Reza Shoja-Razavi, Reza Mozafarinia, Hossein Jamali, Improving the thermal shock resistance of plasma sprayed CYSZ thermal barrier coatings by laser surface modification, Opt. Lasers. Eng. 50 (2012) 780-786.

19. Reza Ghasemi, Reza Shoja-Razavi, Reza Mozafarinia, Hossein Jamali,Morteza Hajizadeh-Oghaz, Raheleh Ahmadi-Pidani, The influence of laser treatment on hot corrosion behavior of plasma-sprayed Nanostructured yttria stabilized zirconia thermal barrier coatings, J. Eur. Ceram. Soc. 34 (2014) 2013-2021.

20. Raheleh Ahmadi-Pidani, Reza Shoja-Razavi, Reza Mozafarinia, Hossein Jamali, Improving the hot corrosion resistance of plasma sprayed CYSZ thermal barrier coatings by laser surface treatment, Mater. Des. 57 (2014) 336-341.

21. C. Zhu, P. Li, A. Javed, G.Y. Liang, P. Xiao, An investigation on the microstructure and oxidation behavior of laser remelted air plasma sprayed thermal barrier coatings, Surf. Coat. Technol. 206 (2012) 3739-3746.

22. L. Wang, J.S. Yang, J.X. Ni, C.G. Liu, X.H. Zhong, F. Shao, H.Y. Zhao, S.Y. Tao, Y. Wang, Influence of cracks in APS-TBCs on stress around TGO during thermal cycling: A numerical simulation study, Surf. Coat. Technol. 201 (2006) 3824-3828.

23. Hui Dong, Guan-Jun Yang, Hong-Neng Cai, Cheng-Xin Li, Chang-Jiu Li, Propagation feature of cracks in plasma-sprayed YSZ coatings under gradient thermal cycling, Ceram. Int. 41 (2015) 3481-3489.

24. Chang-Jiu Li, Yong Li, Guan-Jun Yang, and Cheng-Xin Li, Evolution of Lamellar Interface Cracks During Isothermal Cyclic Test of Plasma-Sprayed 8YSZ Coating with a Columnar-Structured YSZ Interlayer, J. Therm. Spray. Technol. 22 [8] (2013)1374-1382.

25. Zhe Xing, Yong Li, ChangJiu Li, Cheng-Xin Li, Guan-Jun Yang, Influence of Substrate Temperature on Microcracks Formation in Plasma-Sprayed Yttria-Stabilized Zirconia Splats, Key. Eng. Mater. 373 (2008) 69-72.

26. K. Ito, H. Kuriki, M. Enoki, A Numerical Study on Generation Mechanism of Vertical Cracks in Top Coat of TBCs During APS Deposition, J. Therm. Spray. Technol. 24 [5] (2015) 730-738. 
27. K. Ito, H. Kuriki, H. Araki, S. Kuroda, M. Enoki, Evaluation of Generation Mechanism of Vertical Cracks in Top Coat of TBCs During APS Deposition by Laser AE Method, J. Therm. Spray. Technol. 24 [5] (2015) 848-856.

28. C. Zhu, A. Javed, P. Li F. Yang, G.Y. Liang, P. XiaoYa, A study of the microstructure and oxidation behavior of alumina/yttria-stabilized zirconia $\left(\mathrm{Al}_{2} \mathrm{O}_{3} / \mathrm{YSZ}\right)$ thermal barrier coatings, Surf. Coat. Technol. 212 (2012) 214-222.

29. Xin Wang, Mingli Shen, Minghui Chen, Shenglong Zhu, Fuhui Wang, Microstructure stabilization of a novel glass/YSZ composite coating materialby adding alumina particles, Ceram. Int. 41 (2015) 9753-9762.

30. Yanjun Li, Youtao Xie, Liping huang, Xuanyong Liu, Xuebin Zheng, Effect of physical vapor deposited $\mathrm{Al}_{2} \mathrm{O}_{3}$ film on TGO growth in YSZ/CoNiCrAlY coatings, Ceram. Int. 38 (2012) 5113-5121.

31. G. Pulci, J. Tirillò, F. Marra, F. Sarasini, A. Bellucci, T. Valente, C. Bartuli, High temperature oxidation of MCrAlY coatings modified by $\mathrm{Al}_{2} \mathrm{O}_{3}$ PVD overlay, Surf. Coat. Technol. 268 (2015) 198-204.

32. Kun Zhang, Li Liu, Chao Ren, Kai Wang, Guangze Dai, Xuebin Zheng, Yedong He, Preparation of $\mathrm{Al}_{2} \mathrm{O}_{3}-\mathrm{ZrO}_{2}-\mathrm{Y}_{2} \mathrm{O}_{3}$ Composite Coatings by a Modified Sol-Gel Technique for Thermal Barrier Application, Oxid. Met. 80 (2013) 323-339.

33. Lisa Pin, Vanessa Vidal, Fabien Blas, Florence Ansart, Sandrine Duluard, Jean-Pierre Bonin, Yannick Le Maoult, Philippe Lours, Optimized sol-gel thermal barrier coatings for long-term cyclic oxidation life, J. Eur. Ceram. Soc. 34 (2014) 961-974.

34. Morteza Hajizadeh-Oghaz, Reza Shoja Razavi, Ali Ghasemi, Synthesis and characterization of ceria-yttria co-stabilized zirconia (CYSZ) nanoparticles by sol-gel process for thermal barrier coatings (TBCs) applications, J. Sol-Gel. Sci. Technol. 74 (2015) 603-612.

35. A. Gil, V. Shemet, R. Vassen, M. Subanovic, J. Toscano, D. Naumenko, L. Singheiser, W.J. Quadakkers, Effect of surface condition on the oxidation behaviour of MCrAlY coatings, Surf. Coat. Technol. 201 (2006) 3824-3828.

36. M. Gupta, R. Eriksson, U. Sand, P. Nylén, A diffusion-based oxide layer growth model using real interface roughness in thermal barrier coatings for lifetime assessment, Surf. Coat. Technol. 271 (2015) 181-191.

37. Ahmad Keyvani, Microstructural stability oxidation and hot corrosion resistance of nanostructured $\mathrm{Al}_{2} \mathrm{O}_{3} / \mathrm{YSZ}$ composite compared to conventional YSZ TBC coatings, J. Alloy. Comp. 623 (2015) 229-237.

38. M. Nejati, M.R. Rahimipour, I. Mobasherpour, A.H. Pakseresht, Microstructural analysis and thermal shock behavior of plasma sprayed ceria-stabilized zirconia thermal barrier coatings with micro and nano $\mathrm{Al}_{2} \mathrm{O}_{3}$ as a third layer, Surf. Coat. Technol. 282 (2015) 129-138.

39. Xiaofeng Zhang, Kesong Zhou, Shu-juan Dong, Wei Xu, Jin-bing SONG, Min Liu, Effect of Al-deposition on erosion resistance of plasma sprayed thermal barrier coating, Trans. Nonferrous Met. Soc. China 25(2015) 2587-2593. 
40. M. Gupta, R. Eriksson, U. Sand, P. Nylén, A diffusion-based oxide layer growth model using real interface roughness in thermal barrier coatings for lifetime assessment, Surf. Coat. Technol. 271 (2015) 181-191.

41. Mohammadreza Daraanparvar, Muhamad Azizi Yajid, Noordin Mohd Yusof, Saeed Farahany, Mohammad Sakhawat Hussain, Hamid Reza Bakhsheshi-Rad, Z. Valefi, Ahmad Abdolahi, Improvement of thermally grown oxide layer in thermal barrier coating systems with nano alumina as third layer, Trans. Nonferrous Met. Soc. China 23(2013) 1322-1333. 
Table I

Parameters of the HVOF and APS processes

\begin{tabular}{ccc}
\hline Parameters & HVOF & APS \\
\hline Current $(\mathrm{A})$ & $/$ & 625 \\
Power $(\mathrm{KW})$ & $/$ & 47 \\
Primary gas flow $(\mathrm{L} / \mathrm{min})$ & $\left(\mathrm{O}_{2}\right) 900$ & $(\mathrm{Ar}) 38$ \\
Secondary gas flow $(\mathrm{L} / \mathrm{min})$ & $($ kerosene $) 0.43$ & $\left(\mathrm{H}_{2}\right) 13$ \\
Carrier gas $(\mathrm{L} / \mathrm{min})$ & $(\mathrm{Ar}) 7$ & $(\mathrm{Ar}) 4$ \\
Spray distance $(\mathrm{mm})$ & 380 & 110 \\
Powder feed rate $(\mathrm{g} / \mathrm{min})$ & 80 & 35 \\
\hline
\end{tabular}




\section{Table II}

Laser remelting processes for the TBC samples.

\begin{tabular}{ccccc}
\hline No. & Process & Laser remelting & Preheat at $600^{\circ} \mathrm{C}$ & Sol-gel Repairing \\
\hline 1 & APS & $\sqrt{ }$ & \\
2 & Laser remelting & $\sqrt{ }$ & & \\
3 & $\begin{array}{c}\text { Preheating } \\
\text { laser remelting }\end{array}$ & $\sqrt{ }$ & & \\
4 & $\begin{array}{c}\text { Sol-gel repairing } \\
\text { laser remelting }\end{array}$ & $\sqrt{ }$ & & \\
\hline
\end{tabular}


Table III

TGO thickness of APS, laser-remelted, preheating laser-remelted and sol-gel repairing laser-remelted specimens after $100 \mathrm{~h}$ oxidation at $1000^{\circ} \mathrm{C}$

\begin{tabular}{ccccc}
\hline Process & APS & Laser remelting & $\begin{array}{c}\text { Preheat laser } \\
\text { remelting }\end{array}$ & $\begin{array}{c}\text { Sol-gel } \\
\text { Repairing }\end{array}$ \\
\hline TGO Thickness $(\mu \mathrm{m})$ & $5.03 \pm 1.07$ & $4.34 \pm 0.73$ & $3.70 \pm 0.72$ & $3.80 \pm 1.00$ \\
\hline
\end{tabular}




\section{Table IV}

Crack area ratio to laser-remelted and preheating laser-remelted coating surface

\begin{tabular}{ccc|ccc}
\hline \multicolumn{3}{c|}{ Laser remelting } & \multicolumn{3}{c}{ Preheating laser remelting } \\
\hline section & Crack ratio (\%) & Average (\%) & section & Crack ratio (\%) & Average (\%) \\
\hline 1 & 6.27 & 1 & 3.73 & \\
2 & 6.52 & & 2 & 4.25 & \\
3 & 5.72 & $6.46 \pm 0.39$ & 3 & 4.97 & $4.34 \pm 0.44$ \\
4 & 6.59 & & 4 & 4.32 & \\
5 & 6.71 & & 5 & 4.45 & \\
\hline
\end{tabular}




\section{Figure captions}

Fig. 1. Surface images of APS, laser-remelted, preheating laser-remelted and sol-gel repairing laser-remelted coating

Fig. 2. SEM images of the surface of (a) APS coating and (b) laser-remelted coating

Fig. 3. Microstructure of the cross section of laser-remelted coating

Fig. 4. TGO morphology of the specimens after $100 \mathrm{~h}$ oxidation at $1000^{\circ} \mathrm{C}$ (a) APS; (b) laser-remelted; (c) preheating laser-remelted and (d) sol-gel repairing laser-remelted

Fig. 5. A scheme drawing of the calculation method of TGO thickness by Photoshop-AutoCAD

Fig. 6. TGO growth rate of APS, laser-remelted, preheating laser-remelted and sol-gel repairing laser-remelted specimens at $1000^{\circ} \mathrm{C}$

Fig. 7. SEM images of the surface of (a) preheating laser-remelted coating and (b) laser-remelted coating

Fig. 8. A scheme drawing of the calculation method of crack area proportion by Photoshop

Fig. 9. SEM images of sections for crack area proportion calculation on the surface of (a) preheating laser-remelted and (b) laser-remelted coating

Fig. 10. (a) SEM image; (b) EDX spectra; (c) SEM cross section and (d) EDX Al map of sol-gel repairing laser remelted coating 


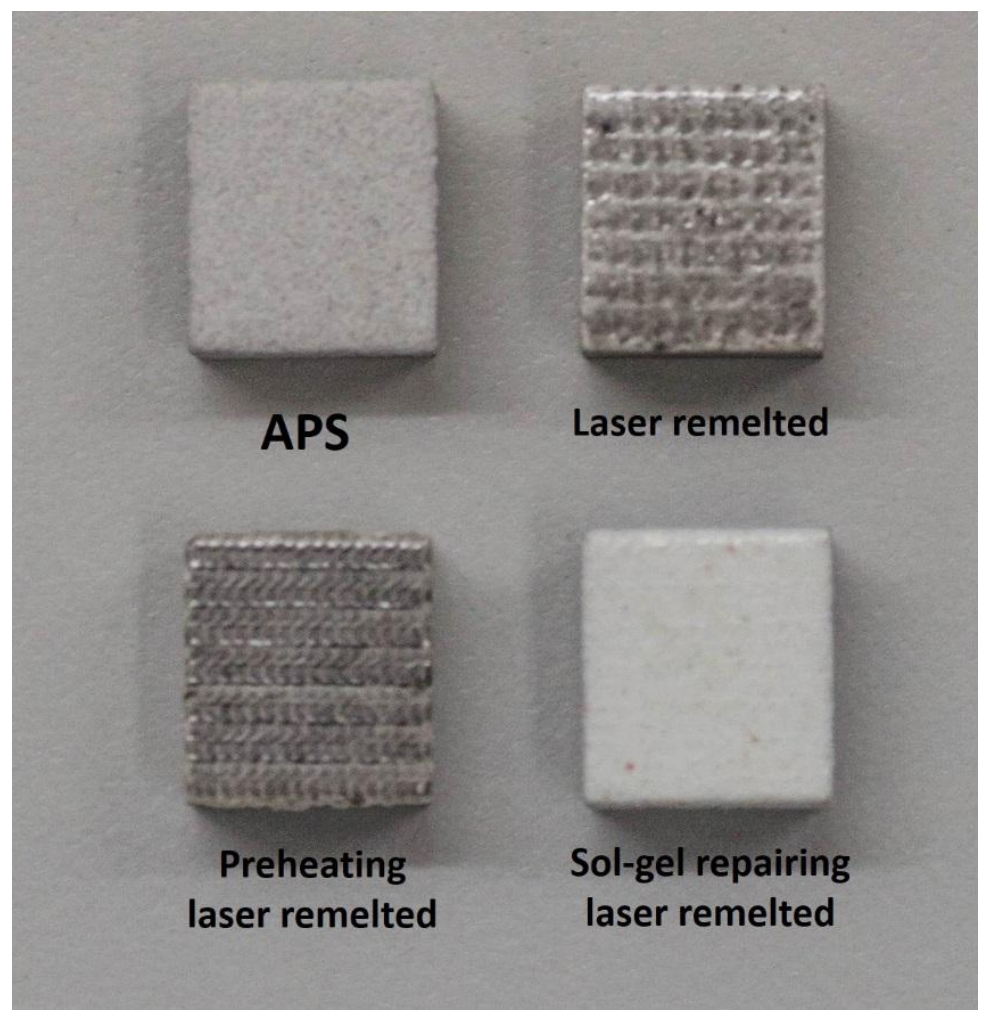

1
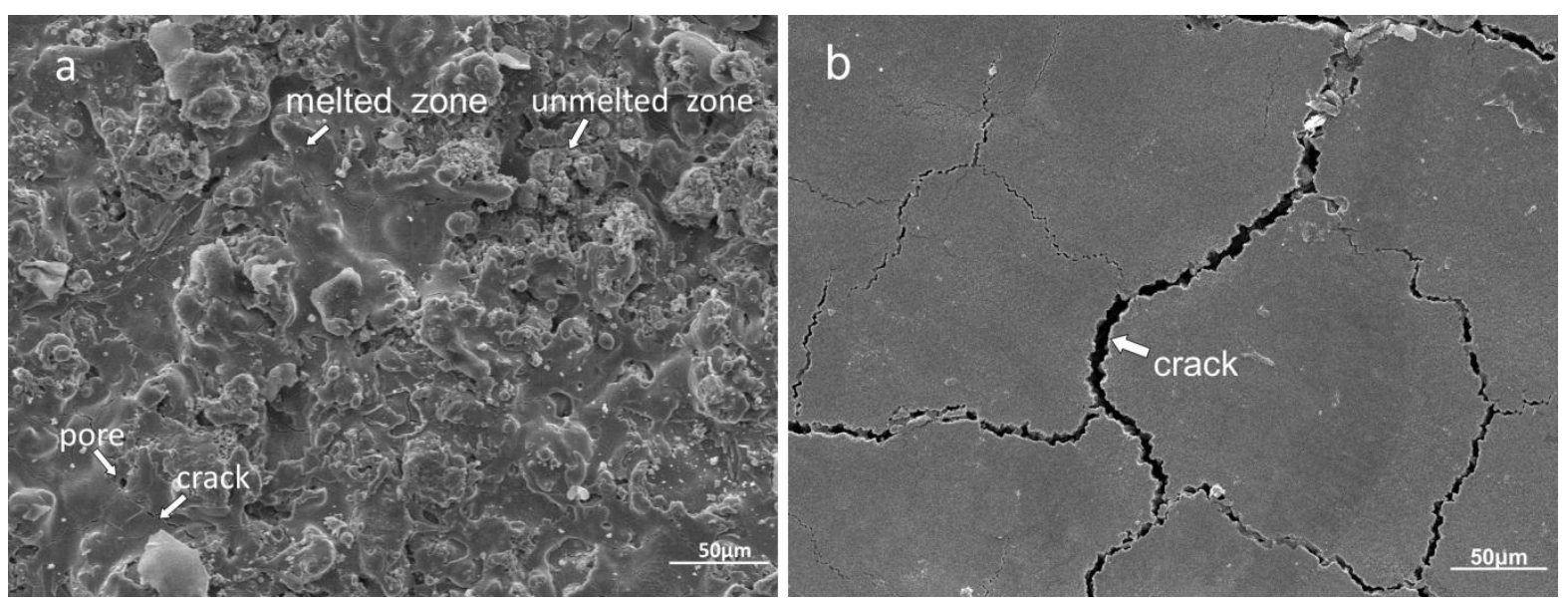

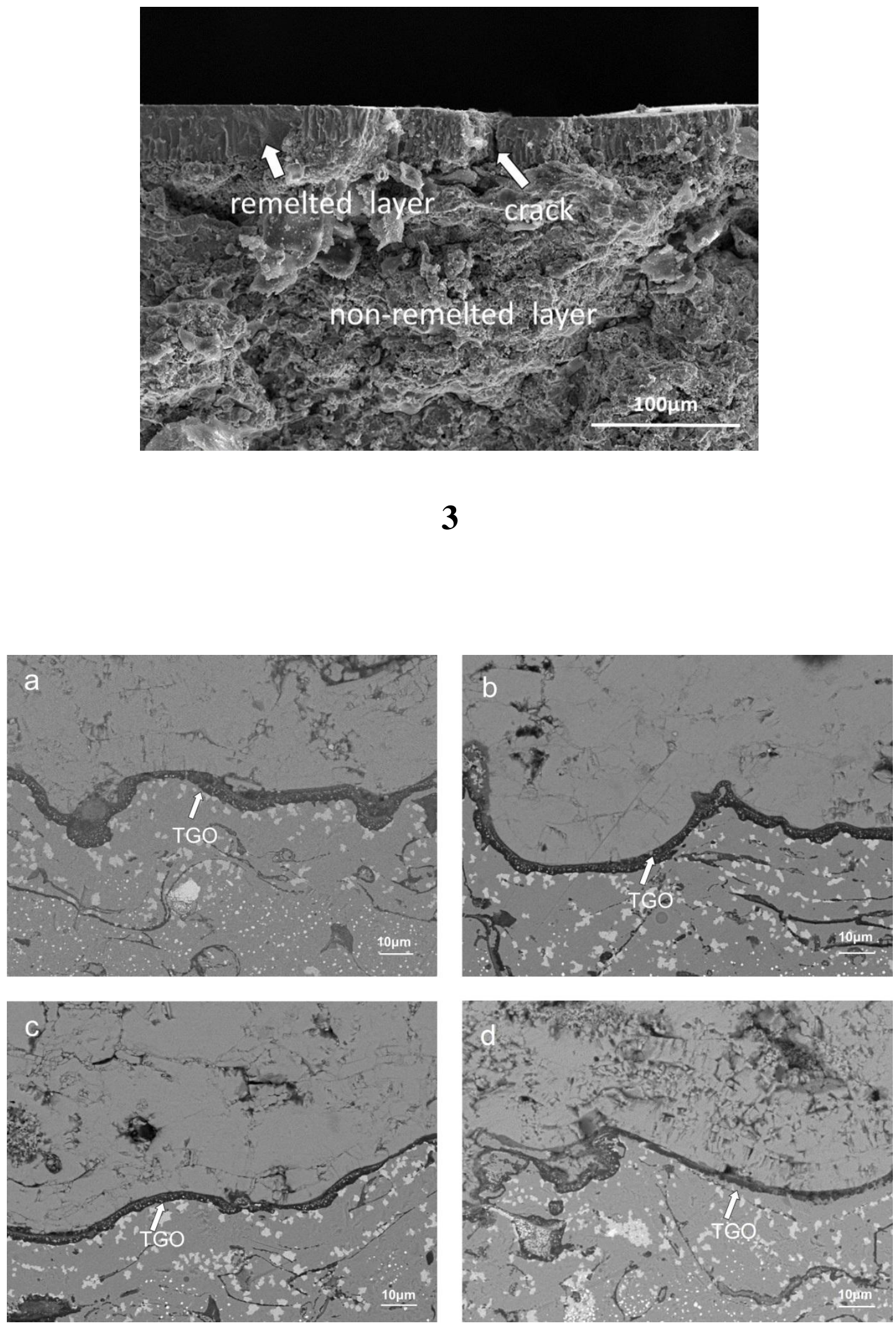

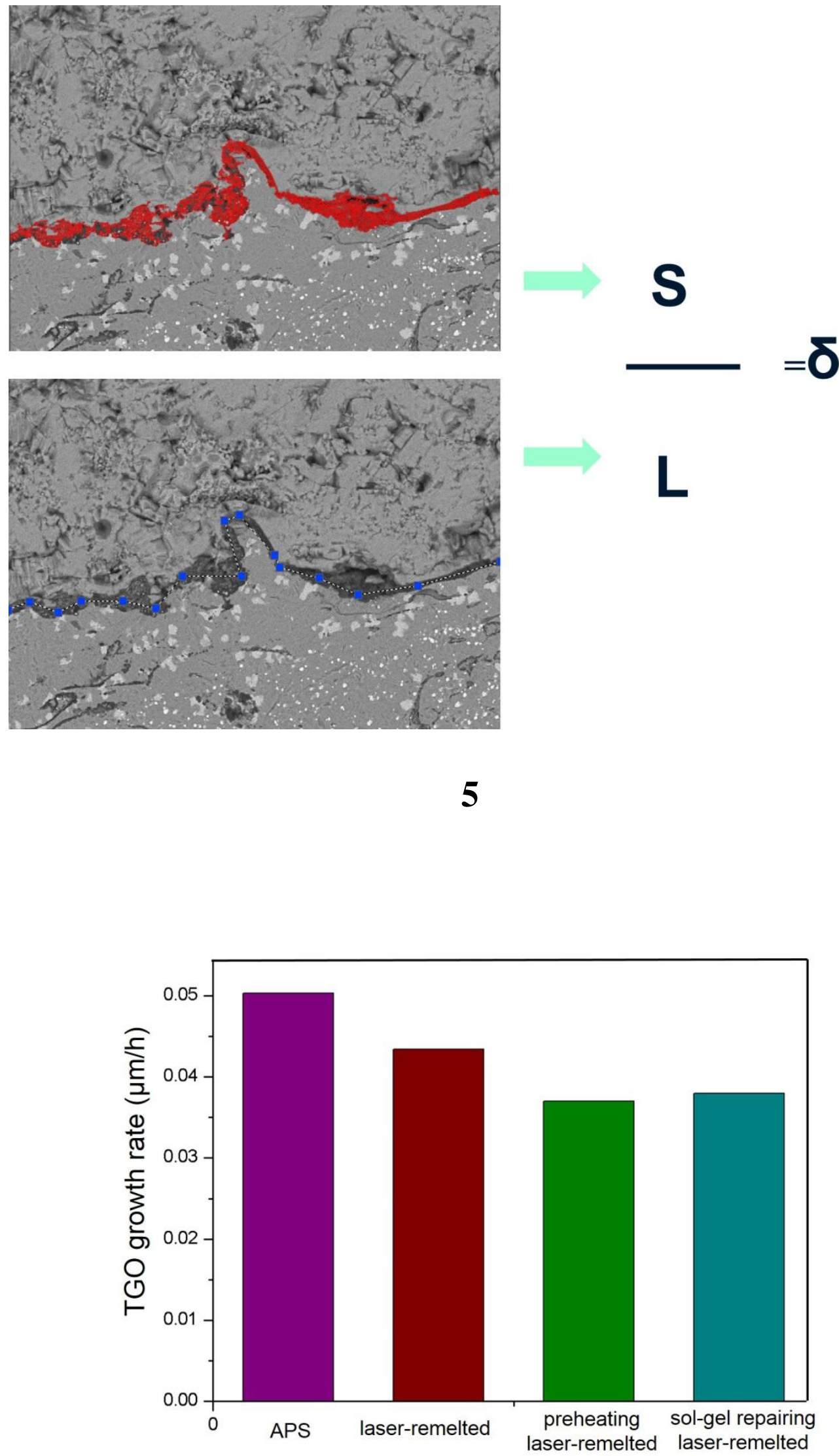

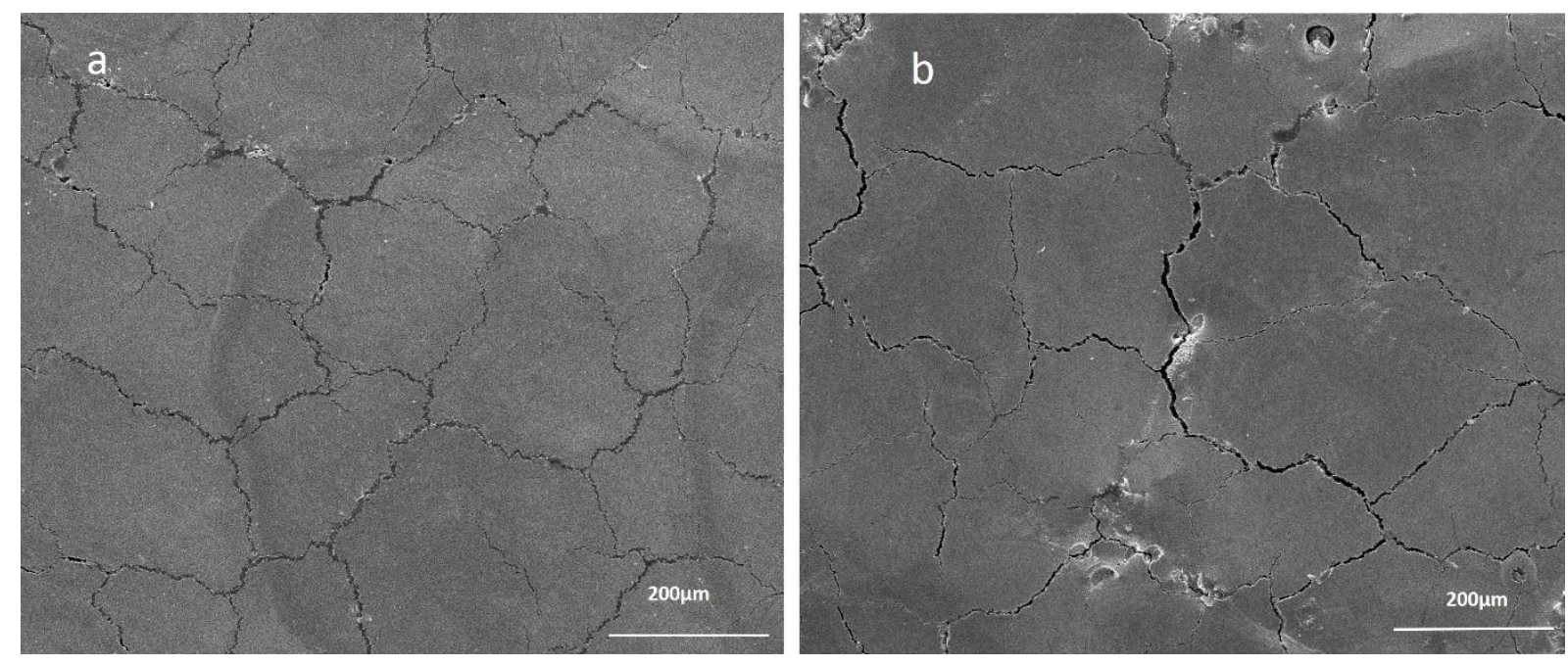

7
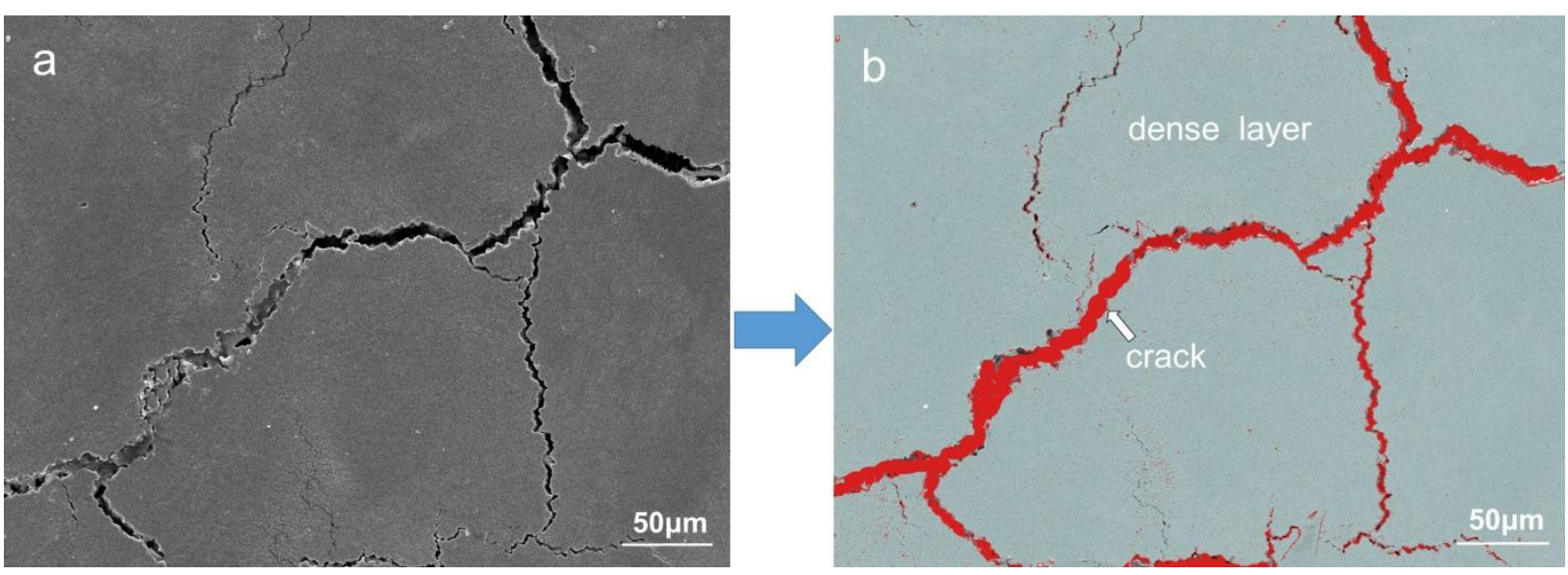

8 

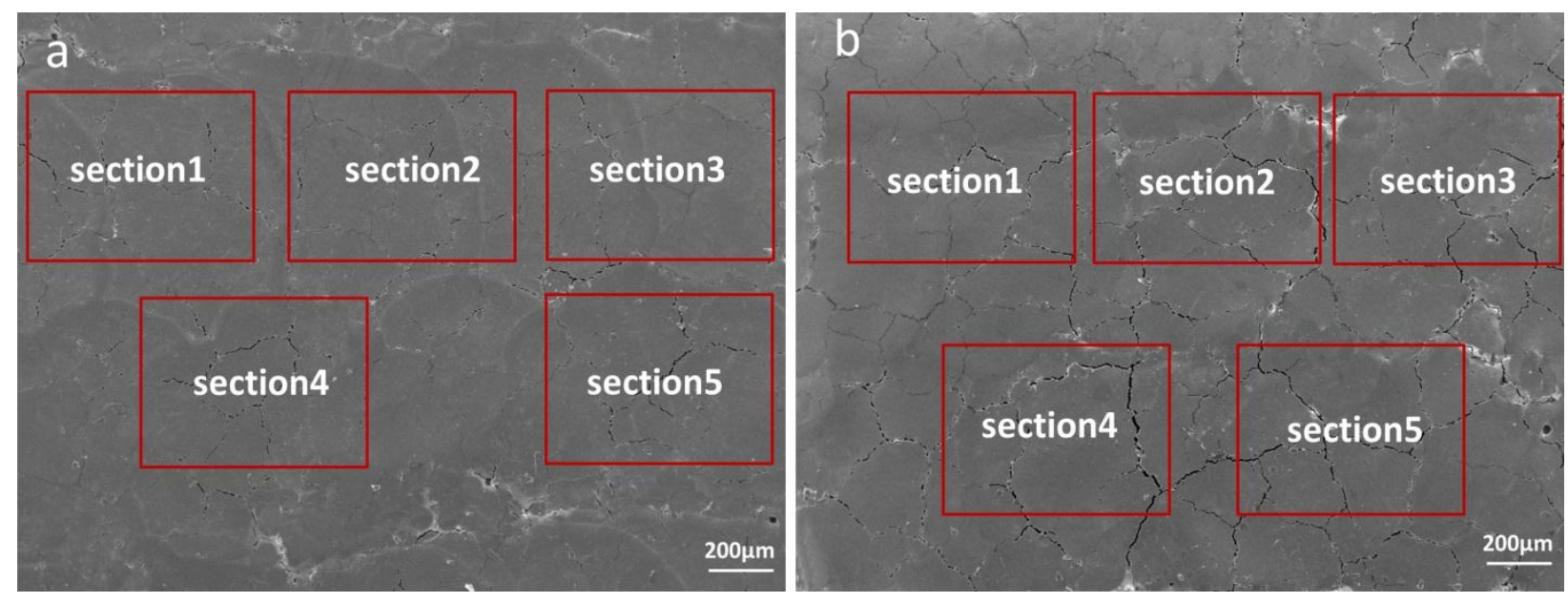

9
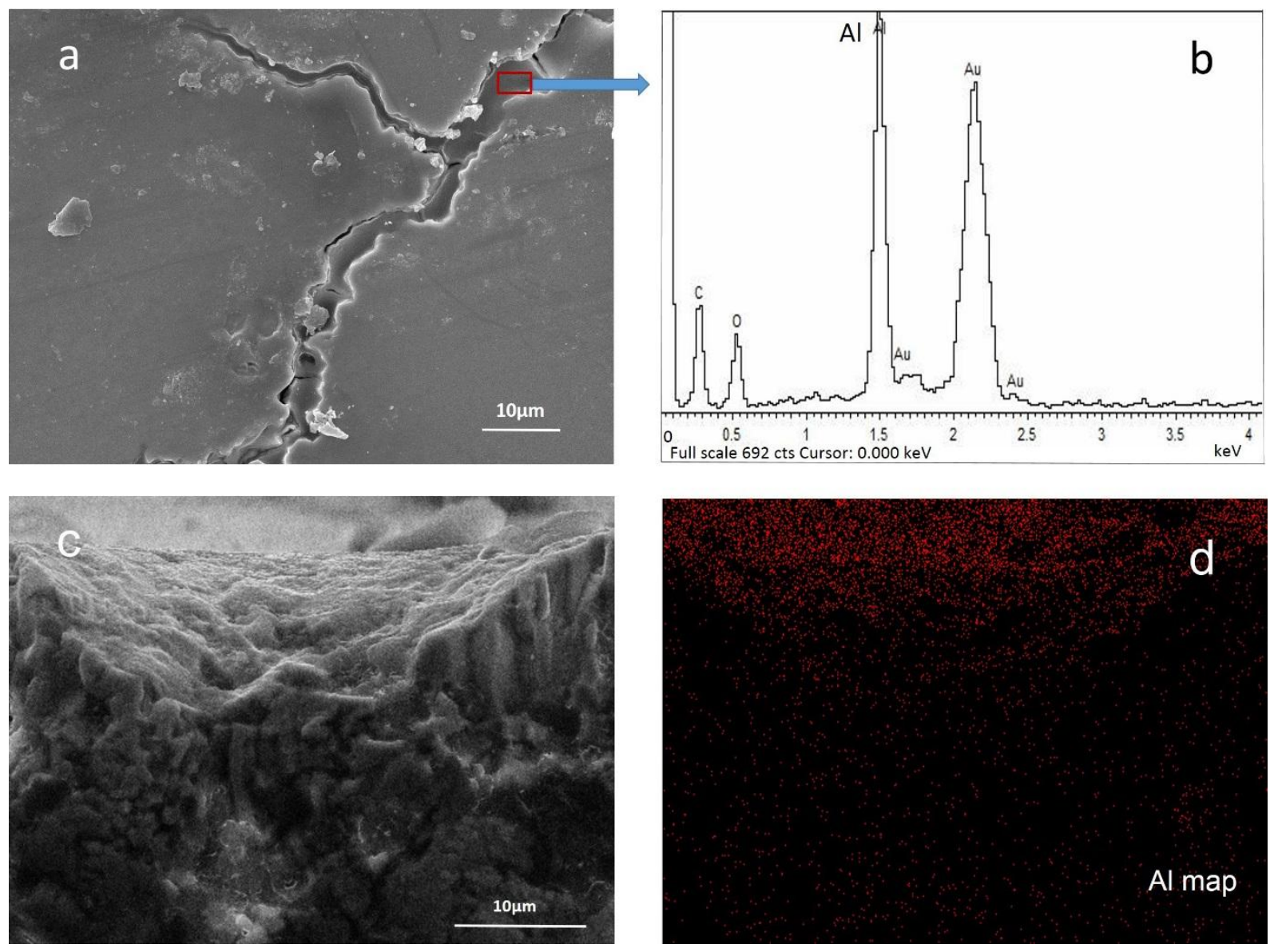